\title{
Control Oriented Model of a Variable Geometry Turbocharger in an Engine with Two EGR Loops
}

\author{
J. Chauvin*, O. Grondin and P. Moulin \\ IFP Energies Nouvelles, 1-4 avenue de Bois-Préau, 92852 Rueil-Malmaison Cedex - France \\ e-mail: jonathan.chauvin@ifpen.fr - olivier.grondin@ifpen.fr - philippe.moulin@ifpen.fr \\ * Corresponding author
}

\begin{abstract}
Résumé - Modélisation de compresseur à géométrie variable dédiée au contrôle pour un moteur avec deux boucles EGR - Afin de rendre les moteurs Diesel modernes plus propres et plus économes en carburant, l'architecture de la boucle d'air est de plus en plus complexe. Les stratégies de contrôle doivent tenir compte des interactions entre les dynamiques et doivent être facilement calibrables. Dans ce contexte, l'utilisation de modèle reposant sur des principes physiques est très adaptée. Dans cet article, nous proposons un modèle d'un turbocompresseur à géométrie variable dans une architecture à deux boucles de recirculation des gaz d'échappement (EGR) : haute pression (HP) et basse pression (BP). Ce modèle est la composante principale d'une stratégie de contrôle et est évalué expérimentalement lors d'essais avec de l'EGR basse pression et de l'EGR haute pression. Les résultats montrent que le choix du circuit EGR a une grande influence sur la position de l'actionneur turbocompresseur, mais que cet effet est bien pris en compte dans le modèle proposé.
\end{abstract}

\footnotetext{
Abstract - Control Oriented Model of a Variable Geometry Turbocharger in an Engine with Two EGR Loops - In order to make modern Diesel engines cleaner and more fuel efficient, their air systems architecture become more and more complex. The control strategies of these systems must take account of the multiple components interactions with minimal calibration effort required. In this context, model based techniques are very attractive. In this paper, we propose a control oriented model of a variable geometry turbocharger in an architecture with two Exhaust Gas Recirculation (EGR) loops: High Pressure (HP) and Low Pressure (LP). This model is implemented in a basic control strategy and evaluated experimentally during tests with LP or HP EGR. The results show that the choice of EGR circuit has a high influence on the turbocharger actuator position, but that this effect is well taken into account in the proposed model.
} 


\section{NOMENCLATURE}

Nomenclature. Comp and turb stands for compressor and turbine respectively.

$P_{u c} \quad$ Comp. upstream pressure $(\mathrm{Pa})$

$P_{d c} \quad$ Comp. downstream pressure $(\mathrm{Pa})$

$T_{u c} \quad$ Comp. upstream temperature (K)

$T_{d c} \quad$ Comp. downstream temperature (K)

$P_{u t} \quad$ Turb. upstream pressure $(\mathrm{Pa})$

$P_{d t} \quad$ Turb. downstream pressure $(\mathrm{Pa})$

$T_{u t} \quad$ Turb. upstream temperature (K)

$\Pi_{c} \quad$ Comp. pressure ratio (-)

$\Pi_{t} \quad$ Turb. pressure ratio (-)

$D_{c} \quad$ Comp. flow (kg.s $\left.\mathrm{s}^{-1}\right)$

$D_{t} \quad$ Turb. flow (kg.s ${ }^{-1}$ )

$D_{e g r, h p} \quad$ HP EGR flow $\left(\mathrm{kg} . \mathrm{s}^{-1}\right)$

$D_{e g r, l p} \quad$ LP EGR flow $\left(\mathrm{kg} . \mathrm{s}^{-1}\right)$

$D_{f} \quad$ Fuel flow (kg.s $\left.\mathrm{s}^{-1}\right)$

$\eta_{c} \quad$ Comp. efficiency (-)

$\eta_{t} \quad$ Turb. efficiency (-)

$N_{t} \quad$ Turb. speed (rd.s $\left.{ }^{-1}\right)$

$\mathrm{u}_{v g t} \quad$ VGT actuator position (\%)

\section{INTRODUCTION}

\subsection{Motivation}

In the automotive industry, the necessary reduction of pollutant emissions involves drastic evolution of engines, and in particular Diesel engines. Exhaust Gas Recirculation (EGR) and turbocharging have been the major evolution of Diesel engines in the recent past. They allow to increase the quantity of burned gas in the intake manifold, which helps reducing the NOx production during the combustion. Two types of EGR systems have been investigated: High Pressure (HP) and Low Pressure (LP) systems, named after their position on the air system with respect to the turbocharger. When both systems are combined, the operating conditions of the turbochargers are highly dependent on the use of either of these two systems. This must be taken into account in the turbocharger control strategy which determines the Variable Geometry Turbocharger (VGT) position corresponding to a required pressure at the outlet of the compressor.

When considering the global system, the problem is multi variables, highly nonlinear, with a lot of interactions between the different subsystems. In this kind of issue, an interesting solution consists in model based techniques which allow to decouple the subsystems and therefore simplify the problem. The global control structure used in our case is described in [1] which also details the strategies for the control of each EGR loop and for the estimation of the intake manifold composition. The present paper aims at complementing this work. It describes the design of a control oriented model of the turbocharger adapted to an engine architecture with two EGR loops. Experimental results are provided to validate the different assumptions. On this topic, not many publications can be found. In [2], the same engine setup is considered, but no details are given for the turbocharger control. The approach proposed here was used before with simpler air system configurations. In [3], it was applied to gasoline engines fitted with fixed geometry turbines. The application to variable geometry turbines was first tried in [4] where it was validated mostly outside the EGR operating area. The purpose in this paper is to extend this approach, and to show that the model proposed can easily be adapted for a system with two EGR circuits.

\subsection{System Description}

The engine considered in this paper is a four cylinder turbocharged Diesel engine shown in Figure 1. Without Exhaust Gas Recirculation, fresh air is aspirated in the engine through the compressor which increases the air density. The air fuel mixture is burnt in the cylinder where the combustion results in the production of mechanical torque. At the exhaust of the system, the turbine converts part of the gas enthalpy into mechanical power on the turbocharger shaft, whose dynamics are the consequence of the balance between the compressor and turbine powers. Two EGR circuits can be used:

- High Pressure EGR: gas from the exhaust manifold are derived to the intake manifold. The EGR dynamics is fast at the price of acting as a discharge for the turbocharger, i.e. less energy is provided to the turbocharger;

- Low Pressure EGR: gas are taken downstream the particulate filter and derived to the upstream of the compressor. On the contrary to the high pressure EGR, this dynamics is much slower but the turbocharger takes all the energy from the exhaust gases.

\subsubsection{Control Input}

The turbocharger is equipped with guide vanes whose angles are adjusted via an actuator that is noted $u_{v g t}$. This affects both the angle of the gas flow on the turbine blades and the turbine effective flow area. By these means, it is possible to maintain a high boost even at low engine speed, and to improve the system dynamics performance.

\subsubsection{Measurements}

The sensors available on the system are the following:

- engine speed $N_{e}$,

- intake manifold pressure and temperature, $P_{d c}$ and $T_{d c}$,

- compressor upstream pressure and temperature, $P_{u c}$ and $T_{u c}$,

- manifold air flow $D_{c}$.

The other variables will be estimated with the measured variables. 


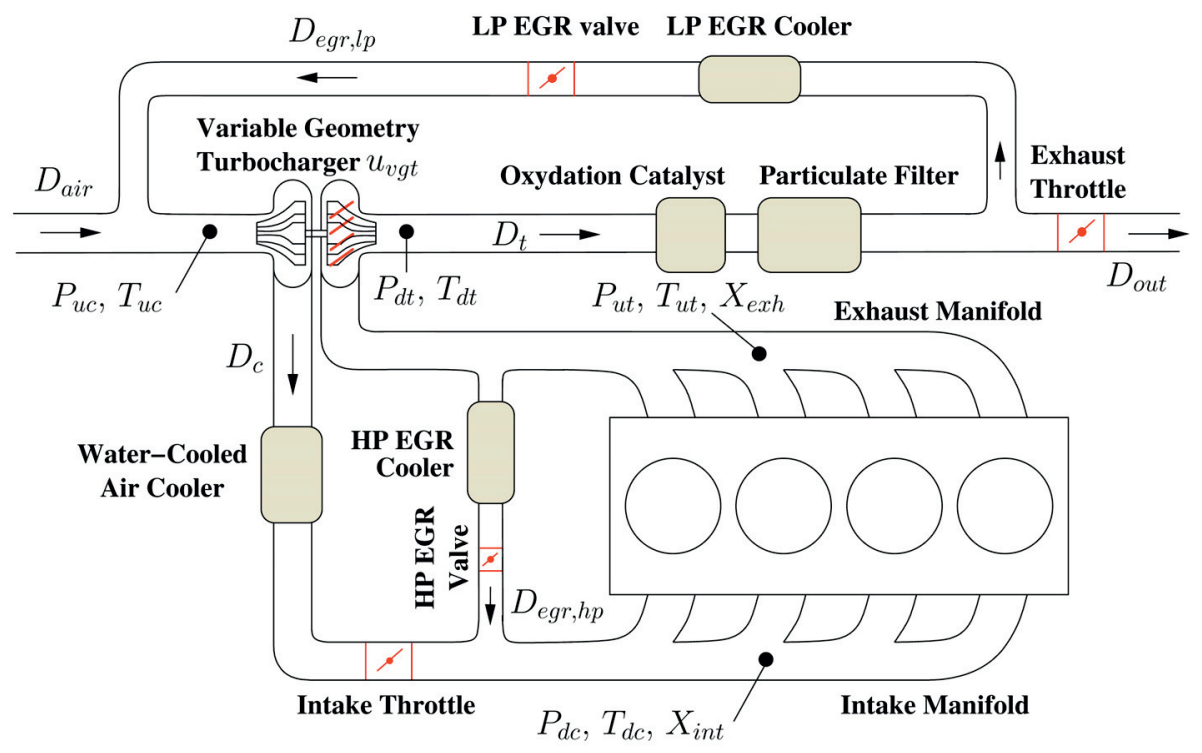

Figure 1

LTC-Diesel engine including a variable geometry turbocharger, a cooled High-Pressure EGR loop and a cooled Low-Pressure EGR loop. Sensors are the engine speed, the intake manifold pressure and temperature $\left(P_{d c}\right.$ and $\left.T_{d c}\right)$, the compressor upstream pressure and temperature, $\left(P_{u c}\right.$ and $\left.T_{u c}\right)$, the compressor air flow $\left(D_{c}\right)$.

\subsection{Model Objective}

First of all, the objective of the model development described here is to provide a basis for the design of a control strategy. The difficulty of this task consists in keeping the right level of complexity. Two main criteria will be considered:

- The model has to represent only the main dynamics governing the evolution of the system in order to minimize the number of states in the controller. The fast dynamics are neglected;

- In an engine, the evolution of a turbocharger depends on the conditions at its boundaries: pressures and temperatures upstream and downstream the compressor and turbine, gas mass flow through these components. This is very important particularly for the architecture with two EGR loops that is considered in this paper. These influences must be represented as far as possible, using measurements when available or estimations otherwise.

As a consequence, some assumptions will have to be made. They will be justified by a comparison between experimental test data and the results of the model.

\section{TURBOCHARGED ENGINE MODEL}

Most of the equations governing the behavior of the turbocompressor can be found in other publications (see for example [5-7]). The novelty of the approach presented here lies in the simplification proposed further and the control strategy designed from the simplified model.

\subsection{Turbocharger Modeling}

The turbocharger is composed by a turbine driven by the exhaust gas and connected via a common shaft to the compressor, which compresses the air in the intake. The rotational speed of the turbocharger shaft $N_{t}$ can be derived from a balance between the turbine power $\mathcal{P}_{t}$ and the compressor power $\mathcal{P}_{c}$

$$
\frac{d}{d t}\left(\frac{1}{2} J_{t} N_{t}^{2}\right)=\mathcal{P}_{t}-\mathcal{P}_{c}
$$

where $\mathrm{J}_{t}$ is the inertia of the turbocharger.

\subsubsection{Compressor}

In order to derive an equation for the compressor power, the first law of thermodynamics is applied. It states that (neglecting heat losses) the compressor power is related to the mass flow through the compressor $D_{c}$ and the total change of enthalpy by $\mathcal{P}_{c}=D_{c} c_{p}\left(T_{d c}-T_{u t}\right)$. The compressor efficiency is introduced as the ratio between isentropic and actual compression powers. The compressor power reads

$$
\mathcal{P}_{c}=D_{c} c_{p} T_{u c} \frac{1}{\eta_{c}}\left(\Pi_{c}^{\frac{\gamma-1}{\gamma}}-1\right)
$$

where $\eta_{c}$ is the compressor efficiency, $\Pi_{c} \triangleq \frac{P_{d c}}{P_{u c}}$ the compressor pressure ratio, and $\gamma$ the specific heat ratio. 


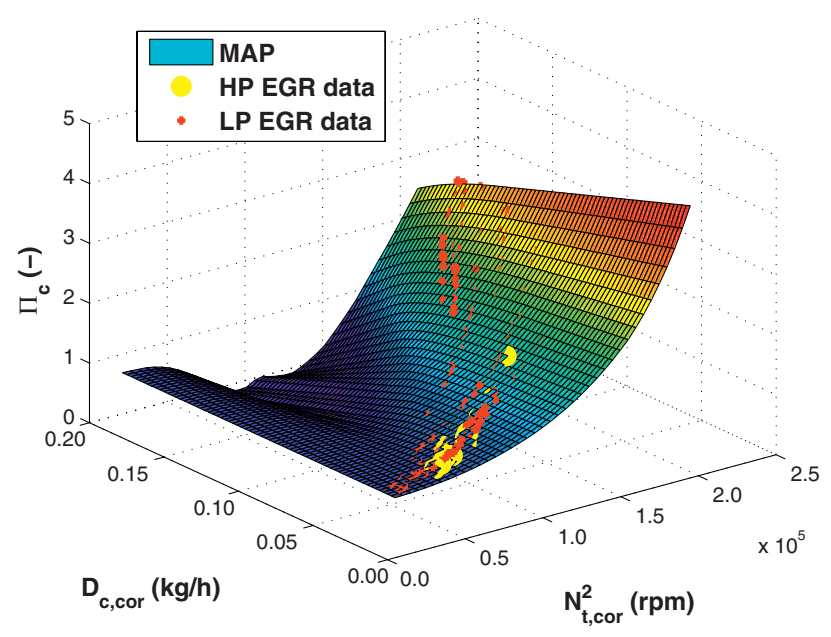

Figure 2

Compressor map. Compressor pressure ratio $\Pi_{c}$ w.r.t. its corrected flow $D_{c, c o r}$ and its corrected speed $N_{c, c o r}$. The blue crosses show the characterization measurements in both the HP and LP EGR loops.

The compressor speed, flow, pressure ratio and efficiency are linked. Different representations can be found in the literature, among which a commonly used one consists in mapping the pressure ratio and efficiency against flow and speed. These maps are extrapolated from data measured during characterization tests. Several extrapolation methods have been proposed (for example [8]). In order to take the variations of the upstream compressor conditions into account, these variables are corrected as follow

$$
D_{c, c o r}=D_{c} \frac{\sqrt{T_{u c}}}{P_{u c}} \text { and } N_{c, c o r}=\frac{N_{t}}{\sqrt{T_{u c}}}
$$

and

$$
\left\{\begin{array}{c}
\Pi_{c}=\phi_{\Pi_{c}}\left(D_{c, c o r}, N_{c, c o r}\right) \\
\eta_{c}=\phi_{\eta_{c}}\left(D_{c, c o r}, N_{c, c o r}\right)
\end{array}\right.
$$

The compressor pressure ratio corresponding to the system studied here is represented in Figure 2.

\subsubsection{Turbine}

Similarly, the turbocharger power is related to the mass flow through the turbine $D_{t}$ and the total change of enthalpy. This results in

$$
\mathcal{P}_{t}=D_{t} c_{p} T_{u t} \eta_{t}\left(1-\Pi_{t}^{\frac{1-\gamma}{\gamma}}\right)
$$

where $\eta_{t}$ is the turbine efficiency, $T_{d t}$ and $P_{d t}$ are the temperature and pressure after the turbine, $P_{u t}$ the exhaust manifold pressure, $\Pi_{t} \triangleq \frac{P_{u t}}{P_{d t}}$ is the turbine pressure ratio and $\gamma$ the specific heat ratio. In this case, the corrected turbine flow $D_{t, c o r}$ and isentropic efficiency $\eta_{t}$ are mapped versus the pressure ratio across the turbine, the corrected turbocharger shaft speed $N_{t, c o r}$, and the VGT actuator position $u_{v g t}$. As for compressor maps, different methods have been proposed to obtain these maps from test data (see [5]). This can be rearranged in the following form, for more commodity:

$$
D_{t}=\phi_{D_{t}}\left(\Pi_{t}, \frac{N_{t}}{\sqrt{T_{u t}}}, u_{v g t}\right) \Pi_{t} \frac{P_{d t}}{\sqrt{T_{u t}}}
$$

\subsection{Engine Modeling}

Conventionally (see [9] for example), we assume that the aspirated flow $D_{a s p}$ can be computed as

$$
D_{\text {asp }}=\eta_{v} \Pi_{c} \Psi
$$

where

$$
\Psi \triangleq \frac{V_{c y l} P_{u c}}{R T_{\text {int }}} \frac{N_{e}}{120}
$$

and $V_{c y l}$ is the cylinder volume. $\eta_{v}$ is the volumetric efficiency. Classically, it is experimentally derived and, eventually, given by a look-up table $\eta_{v}\left(P_{d c}, N_{e}\right)$.

\subsection{Intake and Exhaust Modeling}

We consider the exhaust and intake manifolds as a fixed volume for which the thermodynamics states (pressure, temperature, and composition) are assumed to be homogeneous. The entire volume between the compressor and the engine can be lumped into a single volume. The mass balance in this volume and in the exhaust manifold leads to

$$
\begin{gathered}
\left\{\begin{array}{l}
\frac{d P_{u t}}{d t}=\frac{R T_{u t}}{V_{u t}}\left(D_{a s p}+D_{f}-D_{t}-D_{e g r, h p}\right) \\
\frac{d P_{d t}}{d t}=\frac{R T_{d t}}{V_{d t}}\left(D_{t}-D_{o u t}-D_{e g r, l p}\right)
\end{array}\right. \\
\left\{\begin{array}{l}
\frac{d P_{u c}}{d t}=\frac{R T_{u c}}{V_{u c}}\left(D_{a i r}+D_{e g r, l p}-D_{c}\right) \\
\frac{d P_{d c}}{d t}=\frac{R T_{d c}}{V_{d c}}\left(D_{c}+D_{e g r, h p}-D_{a s p}\right)
\end{array}\right.
\end{gathered}
$$

\subsection{Summary}

Gathering Equations (1-8) leads to the following dynamics

$$
\left\{\begin{aligned}
\frac{d}{d t}\left(\frac{1}{2} J_{t} N_{t}^{2}\right)= & \alpha_{t} \phi_{D_{t}}\left(\Pi_{t}, \frac{N_{t}}{\sqrt{T_{u t}}}, u_{v g t}\right) \phi_{t}\left(\Pi_{t}\right) \\
& -D_{c} c_{p} T_{u c} \frac{1}{\eta_{c}} \phi_{c}\left(\Pi_{c}\right) \\
\frac{d P_{u t}}{d t}= & \frac{R T_{u t}}{V_{u t}}\left(\eta_{v} \Pi_{c} \Psi+D_{f}-D_{e g r, h p}\right. \\
& \left.-\phi_{D_{t}}\left(\Pi_{t}, \frac{N_{t}}{\sqrt{T_{u t}}}, u_{v g t}\right) \Pi_{t} \frac{P_{d t}}{\sqrt{T_{u t}}}\right) \\
= & \frac{R T_{d t}}{V_{d t}}\left(\phi_{D_{t}}\left(\Pi_{t}, \frac{N_{t}}{\sqrt{T_{u t}}}, u_{v g t}\right) \Pi_{t} \frac{P_{d t}}{\sqrt{T_{u t}}}\right. \\
& \left.-D_{\text {out }}-D_{e g r, l p}\right) \\
\frac{d P_{d t}}{d t}= & \frac{R T_{u c}}{V_{u c}}\left(D_{a i r}+D_{e g r, l p}-D_{c}\right) \\
= & \frac{R T_{d c}}{V_{d c}}\left(D_{c}+D_{e g r, h p}-\eta_{v} \Pi_{c} \Psi\right)
\end{aligned}\right.
$$


where $\phi_{t}(\Pi) \triangleq \Pi\left(1-\Pi^{\frac{1-\gamma}{\gamma}}\right), \phi_{c}(\Pi) \triangleq \Pi^{\frac{\gamma-1}{\gamma}}-1$, and $\alpha_{t} \triangleq P_{d t} c_{p} T_{u t} \eta_{t} \sqrt{T_{u t}}$. This model takes account of parameters external to the turbocharger itself: temperatures upstream the compressor and turbine, pressure downstream the turbine. However, it contains five states. Since the ultimate purpose of this work is to design a model based control law, further simplifications have to be undertaken. Different types of assumptions will be made and verified experimentally.

\section{MODEL REDUCTION}

The first type of assumptions concerns the dynamics. The second type concerns the steady state dependencies. The purpose is to keep only the relevant dynamics of the system, and parameters that can be measured or estimated from the available sensors.

\subsection{Dynamic Simplification: Model Simplification by Singular Perturbation}

The fifth order nonlinear system (9) accurately describes the dynamics of the system. However, one can notice that the turbocharger speed is much slower than the pressure dynamics. Indeed, typically we have $\frac{V_{u t}}{R T_{u t}} \simeq 5 e-9$, $\frac{V_{d c}}{R T_{d c}} \simeq 5 e-8$ and $J_{t}=3 e-5$. This suggests to simplify these dynamics with a singular perturbation method [10]. Let $\epsilon \triangleq \frac{V_{u t}}{R T_{u t}}$ be a scalar that represents all the small parameters to be neglected. The reference dynamics (9) has the form of the standard singularly perturbed system

$$
\left\{\begin{aligned}
\dot{z}_{1} & =\phi\left(z_{1}, z_{2}, u\right) \\
\epsilon \dot{z}_{2} & =\psi\left(z_{1}, z_{2}, \epsilon\right)
\end{aligned}\right.
$$

where $z_{1} \triangleq N_{t}, z_{2} \triangleq\left[P_{u c} P_{d c} P_{u t} P_{d t}\right]^{T}$. In other words, we split the slow $z_{1}$-dynamics (the power balance) and the $z_{2}$-fast dynamics (mass balances).

The equation $\psi\left(z_{1}, z_{2}, 0\right)=0$ has a unique root of interest $z_{2}=h\left(z_{1}\right)$. In details, it is

$$
\left\{\begin{array}{c}
\eta_{v} \Pi_{c} \Psi+D_{f}-D_{e g r, h p}=\phi_{D_{t}}\left(\Pi_{t}, \frac{N_{t}}{\sqrt{T_{u t}}}, u_{v g t}\right) \Pi_{t} \frac{P_{d t}}{\sqrt{T_{u t}}} \\
D_{\text {out }}+D_{e g r, l p}=\phi_{D_{t}}\left(\Pi_{t}, \frac{N_{t}}{\sqrt{T_{u t}}}, u_{v g t}\right) \Pi_{t} \frac{P_{d t}}{\sqrt{T_{u t}}} \\
D_{\text {in }}+D_{e g r, l p}=D_{c} \\
D_{c}+D_{e g r, h p}=\eta_{v} \Pi_{c} \Psi
\end{array}\right.
$$

To ensure the validity of the simplification, we can check the uniform stability of the Jacobian of $\psi$ as shown in [11] [Assumption $3.2 \mathrm{p} .11$ ]. These dynamics are stable as shown in [3]. The reduced dynamics writes

$$
\left\{\begin{array}{l}
\dot{\bar{z}}_{1}=\phi\left(\bar{z}_{1}, h\left(\bar{z}_{1}\right), u\right) \\
\bar{z}_{2}=h\left(\bar{z}_{1}\right)
\end{array}\right.
$$

From [10] [Th 11.1], the following proposition holds
Proposition 1 Consider the singularly perturbated system (10) and $z_{2}=h\left(z_{1}\right)$ the isolated root of $\psi\left(z_{1}, z_{2}\right)=0$. There exists a positive constant $\epsilon^{\star}>\epsilon>0$ such that (10) possesses a unique trajectory $z_{1}(t, \epsilon), z_{2}(t, \epsilon)$, and

$$
\begin{gathered}
z_{1}(t, \epsilon)-\bar{z}_{1}(t)=O(\epsilon) \\
z_{2}(t, \epsilon)-h\left(\bar{z}_{1}(t)\right)=O(\epsilon)
\end{gathered}
$$

hold when $\epsilon<\epsilon^{\star}$.

Thus, the new reference system writes

$$
\left\{\begin{array}{c}
\frac{d}{d t}\left(\frac{1}{2} J_{t} N_{t}^{2}\right)=\phi_{D_{t}}\left(\Pi_{t}, \frac{N_{t}}{\sqrt{T_{u t}}}, u_{v g t}\right) c_{p} P_{d t} \sqrt{T_{u t}} \eta_{t} \phi_{t}\left(\Pi_{t}\right) \\
\quad-\left(\eta_{v} \Pi_{c} \Psi-D_{e g r, h p}\right) c_{p} T_{u c} \frac{1}{\eta_{c}} \phi_{c}\left(\Pi_{c}\right) \\
\eta_{v} \Pi_{c} \Psi=\phi_{D_{t}}\left(\Pi_{t}, \frac{N_{t}}{\sqrt{T_{u t}}}, u_{v g t}\right) \frac{P_{d t}}{\sqrt{T_{u t}}} \\
\quad-D_{f}+D_{e g r, h p}
\end{array}\right.
$$

The simplified dynamics write now as a first order nonlinear dynamics with an algebraic equation, the steady state solution of the intake and exhaust dynamics

\subsection{Steady State Assumptions}

\subsubsection{High Pressure Flow Simplification}

Contrary to the turbocharger, the high pressure EGR loop has a direct control, i.e. the EGR valve controls directly this flow. Again, simplification is made in order to substitute the high pressure EGR flow by its reference value that is directly linked to the intake pressure. We introduce variable $\delta_{H P}$ to characterize the choice of EGR circuit: when HP EGR is used $\delta_{H P}$ is equal to 1 , it is equal to 0 otherwise. With this notation, we have:

$$
D_{e g r, h p}=\frac{X_{\text {int }} \delta_{H P}}{X_{\text {exh }}} \eta_{\text {vol }} \Pi_{c} \Psi
$$

where $X_{\text {int }}\left(\right.$ resp $\left.X_{\text {exh }}\right)$ is the intake (resp. exhaust) burned gas ratio.

\subsubsection{Turbine Flow Simplification}

The turbine can be considered as a restriction on the exhaust gas flow. However, the standard equation for compressible flow across an orifice cannot be applied in this case. Modified versions of this equation have been proposed which fit better the experimental results, based on various assumptions (see [7]). Most of them neglect the influence of the turbine speed. The formula kept in the present case is given below, the justification being that it shows a good correlation with the characterization data (see Fig. 3).

$$
D_{t}=\frac{P_{d t}}{\sqrt{T_{u t}}} \phi_{t u r b}\left(\Pi_{t}\right) \psi_{v g t}\left(u_{v g t}\right)
$$

where $\psi_{v g t}\left(u_{v g t}\right)$ is equivalent to an effective area (represented in Fig. 4) and

$$
\phi_{t u r b}\left(\Pi_{t}\right) \triangleq \frac{\Pi_{t}^{\frac{3}{2}}}{\sqrt{R}} \sqrt{\frac{2 \gamma}{\gamma-1}\left(\Pi_{t}^{\frac{-2}{\gamma}}-\Pi_{t}^{\frac{-\gamma-1}{\gamma}}\right)}
$$




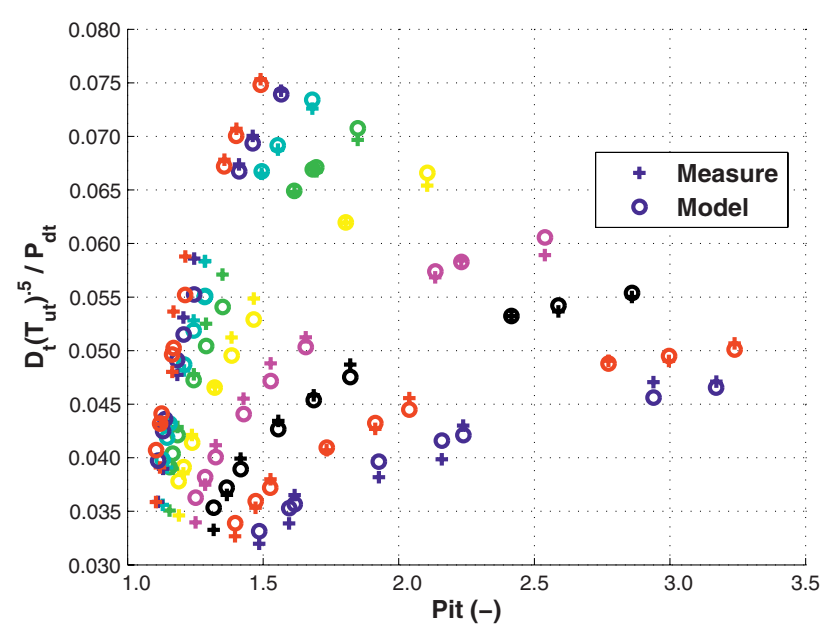

Figure 3

Comparison between the measured corrected turbine flow $D_{t} \frac{\sqrt{T_{u t}}}{P_{d t}}$ and its simplified modeling for several value of the VGT position.

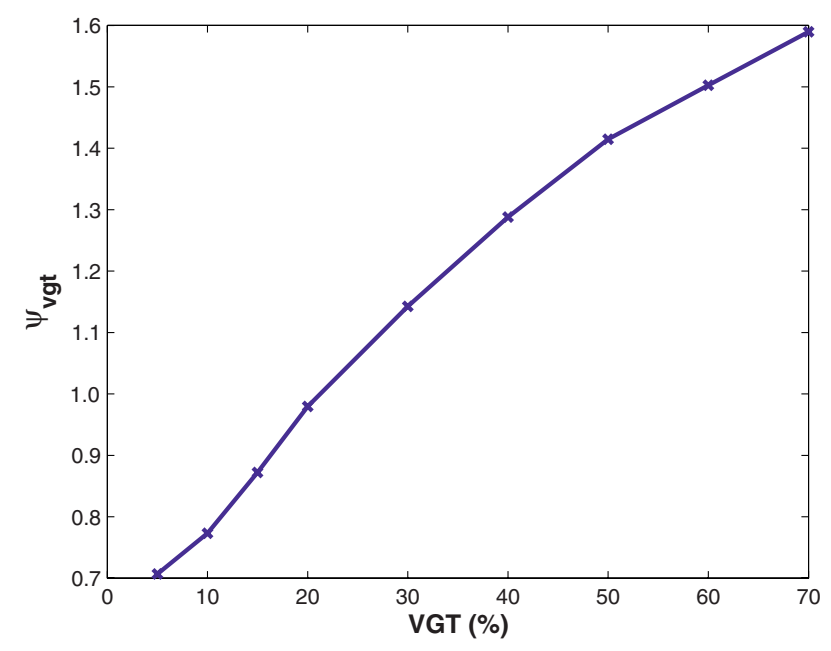

Figure 4

Function $\psi_{v g t}$ with respect to the control input $u_{v g t}$.

\subsubsection{Correlation between the Turbocharger Speed and the Intake Pressure}

For given engine operating conditions, the turbocharger speed and the intake pressure are very correlated. It is therefore interesting to consider the combination of (3) and (6). The corrected compressor flow depends on the compressor pressure ratio, the engine speed and the operating conditions, and:

$$
\Pi_{c}=\phi_{\Pi, c}\left(\eta_{v}\left(\Pi_{c} P_{u c}, N_{e}\right) \Pi_{c} \Psi, \frac{N_{t}}{\sqrt{T_{u c}}}\right)
$$

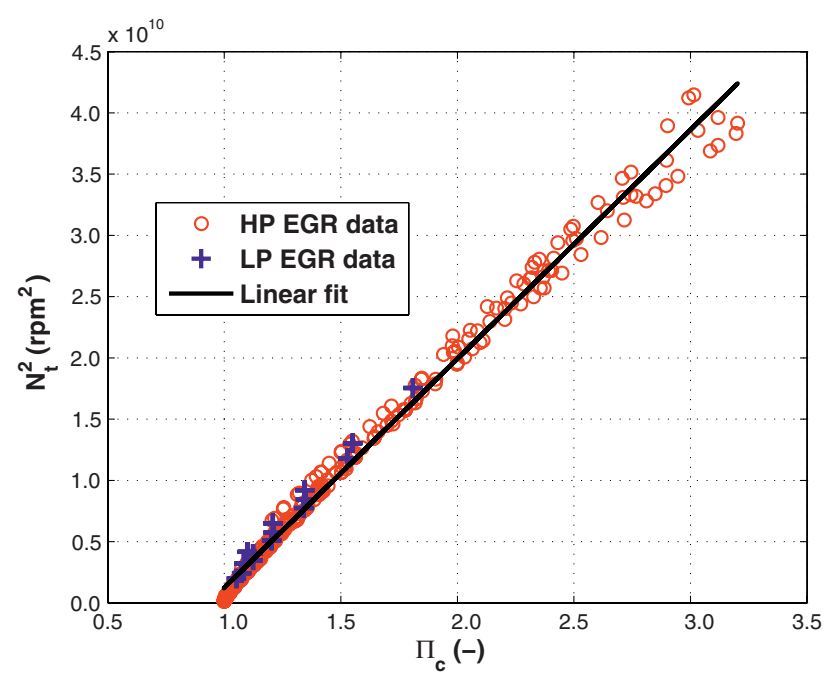

Figure 5

Experimental results at steady state. Variation of the turbocharger speed square $N_{t}^{2}$ w.r.t. the compressor pressure ratio $\Pi_{c}$.

This expression is remarkable since it shows a direct dependency between the compressor pressure ratio and the engine speed. The influence of the intake temperature is of second order and will be neglected. The following graph shows experimental measurements. As experimentally represented in Figure 5, we can estimate the turbocharger speed square $N_{t}^{2}$ linearly w.r.t. the compressor pressure ratio $\Pi_{c}$, i.e.

$$
N_{t}^{2}=a \Pi_{c}+b
$$

\subsubsection{Steady State Assumptions}

The system dynamics depend on a lot of different variables that physically are related to the engine operating conditions (engine speed, volumetric efficiency) or the environment (compressor upstream pressure and temperature, turbine downstream pressure). Since they are external to the turbocharger, we will make the assumption that they depend on the operating point of the engine. They can either be measured or estimated based on steady state maps.

The only remaining unknown terms in the system of Equations (12) are $\eta_{c}$ and $\eta_{t}$. Since they vary in small proportions on the engine operating points, we will also consider that they can be mapped as functions of the engine operating conditions. It is difficult to validate it in transient since it is not possible to measure the efficiencies in this case. The correct behavior of the control law designed from these assumptions will validate them a posteriori. 


\subsection{Reference System}

The linear correlation between compressor pressure ratio and turbocharger kinetic energy considerably simplifies the studied system. The state variable can be chosen as the compressor pressure ratio, and the turbocharger speed does not appear any more in the model equations.

The reference system writes

$$
\left\{\begin{array}{l}
\dot{\Pi}_{c}=\alpha_{1}\left(\beta \Pi_{c}+D_{f}\right) \psi_{t}\left(\Pi_{t}\right)-\alpha_{2} \beta \psi_{c}\left(\Pi_{c}\right) \\
\Pi_{c}=\alpha_{3}\left(\phi_{t u r b}\left(\Pi_{t}\right) \psi_{v g t}\left(u_{v g t}\right)-\alpha_{4}\right)
\end{array}\right.
$$

where $\left\{\alpha_{i}\right\}_{i \in[1,4]}$ depend on the engine operating conditions:

$$
\left\{\begin{array}{c}
\beta=\left(1-\frac{X_{i n t} \delta_{H P}}{X_{e x h}}\right) \eta_{v} \Psi \\
\alpha_{1}=c_{p} T_{u t} \eta_{t} \frac{2}{J_{t} \mathrm{a}} \text { and } \alpha_{2}=c_{p} T_{u c} \frac{1}{\eta_{c}} \frac{2}{J_{t} \mathrm{a}} \\
\alpha_{3}=\frac{P_{d t}}{\beta \sqrt{T_{u t}}} \text { and } \alpha_{4}=\frac{\sqrt{T_{u t} D_{f}}}{P_{d t}}
\end{array}\right.
$$

The first equation of system (14) represents the balance between compressor and turbine mechanical power, giving the dynamics of the system. The second equation represents the mass conservation in the exhaust manifold, the dynamics being neglected.

The functions $\phi_{t u r b}, \psi_{v g t}, \psi_{c}$ and $\psi_{t}$ are nonlinear but invertible. This property is very important and will be used when designing the control law.

The coefficients $\alpha_{i}$ can be computed from sensors available on the engine. Variable $\beta$ represents the gas mass flow through the compressor and through the turbine. Only this variable depends on the EGR loop choice.

\section{ONLINE MODEL VALIDATION}

The purpose of this paper is not to describe the design of a control strategy already presented in [12]. However, since model (14) is intended for control, the validation can be made online after implementing it in a control structure. In this section we briefly describe the control structure chosen for the validation, and then we show the experimental results.

\subsection{Control Implementation}

Model (14) was inverted and implemented in a control strategy. A possible implementation structure was proposed in [4]. Other solutions would be possible. The model validity does not depend on the control structure, but we chose in this work to keep a similar implementation. The basic structure of the strategy is represented in Figure 6. Controller $C$ consists in a linear PI controller. Its output is added to a feedforward term and transformed into an actuator setpoint in $M^{-1}$. Controller $C$ is built so that

$$
\overbrace{\Pi_{c, s p}-\Pi_{c}}=-\mu_{p}\left(\Pi_{c, s p}-\Pi_{c}\right)-\mu_{i} \int\left(\Pi_{c, s p}-\Pi_{c}\right)
$$

where $\mu_{p}$ and $\mu_{i}$ are proportional and integral gains.

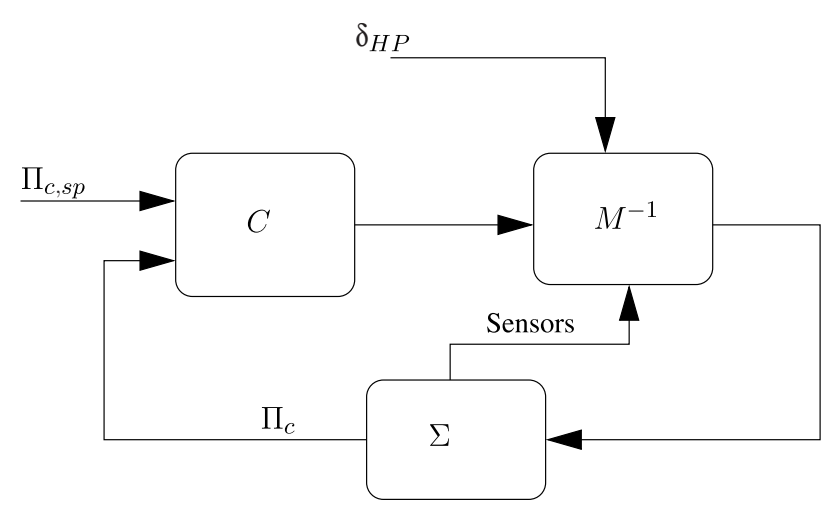

Figure 6

Turbocharger control structure.

The actuator setpoint is computed by:

$$
\left\{\begin{aligned}
\dot{z} & =\Pi_{c, s p}-\Pi_{c} \\
C & =\mu_{p}\left(\Pi_{c, s p}-\Pi_{c}\right)+\mu_{i} z \\
\Pi_{t, s p} & =\psi_{t}^{-1}\left(\left(C+\alpha_{2} \beta \psi_{c}\left(\Pi_{c, s p}\right)\right) \frac{1}{\alpha_{1}\left(\beta \Pi_{c, s p}+D_{f}\right)}\right) \\
u_{v g t, s p} & =\psi_{v g t}^{-1}\left(\left(\frac{\Pi_{c, s p}}{\alpha_{3}}+\alpha_{4}\right) \frac{1}{\phi_{t u r b}\left(\Pi_{t}\right)}\right)
\end{aligned}\right.
$$

where subscript $s p$ stands for set-point. Controller $C$ follows from the two first lines, whereas the last two lines are the inversion of (14). Variable $z$ is the state of the controller. In steady state when the intake manifold pressure is controlled to the setpoint, an indication of the accuracy of model 14 is given by the relative importance of $C$ with respect to the feedforward term $\alpha_{2} \beta \psi_{c}\left(\Pi_{c, s p}\right)$.

\subsection{Experimental Results}

Load transient tests at constant speed have been performed in HP or LP EGR configurations. The results are reported in Figures 7, 8, 9 and 10 which show respectively the intake manifold pressure, the intake manifold burned gas rate, the turbocharger actuator (VGT) and the controller output compared to the feedforward term. In each figure a test performed with HP EGR is compared with a test in LP EGR mode. The intake manifold conditions (composition and pressure) are controlled to the same values (Fig. 7 and 8) ${ }^{(1)}$, but the VGT has to be actuated at very different positions (Fig. 9) due to the differences in mass flow through turbine and compressor. However, the correction necessary from controller $C$ is similar in each mode and stays at low levels compared to the feedforward term (Fig. 10). The operating conditions of the turbocharger highly depends on the flow through the compressor and turbine, and hence on the choice of EGR circuit. This is why the VGT is positioned at very

(1) Notice that the BGR controller could be re-tuned for the LP case to decrease the oscillations. 


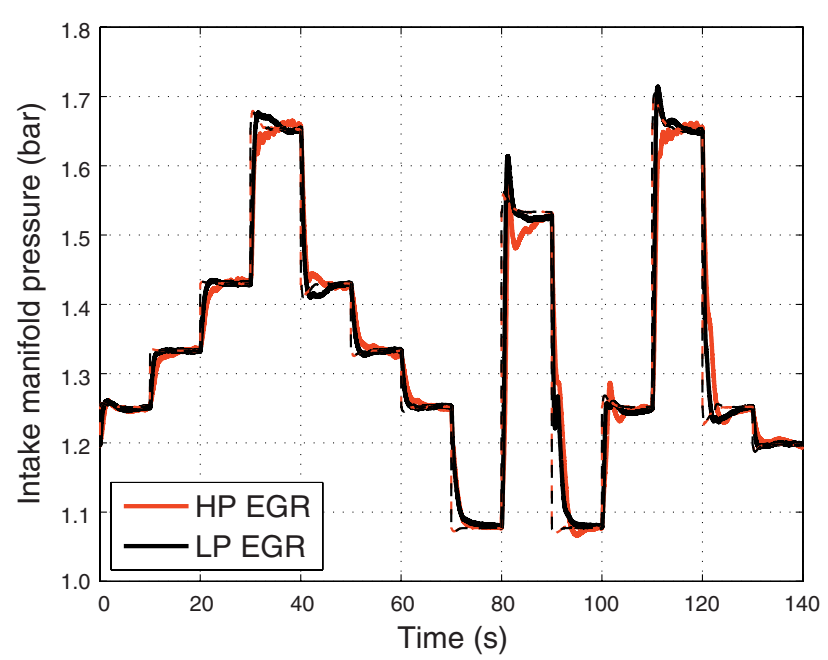

Figure 7

Intake manifold pressure with HP or LP EGR.

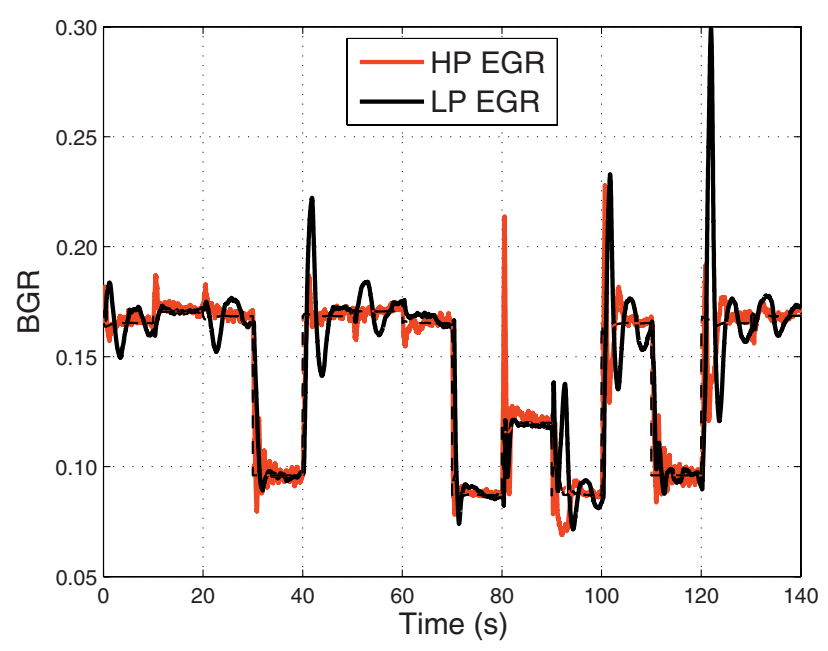

Figure 8

Estimated intake manifold BGR with HP or LP EGR.

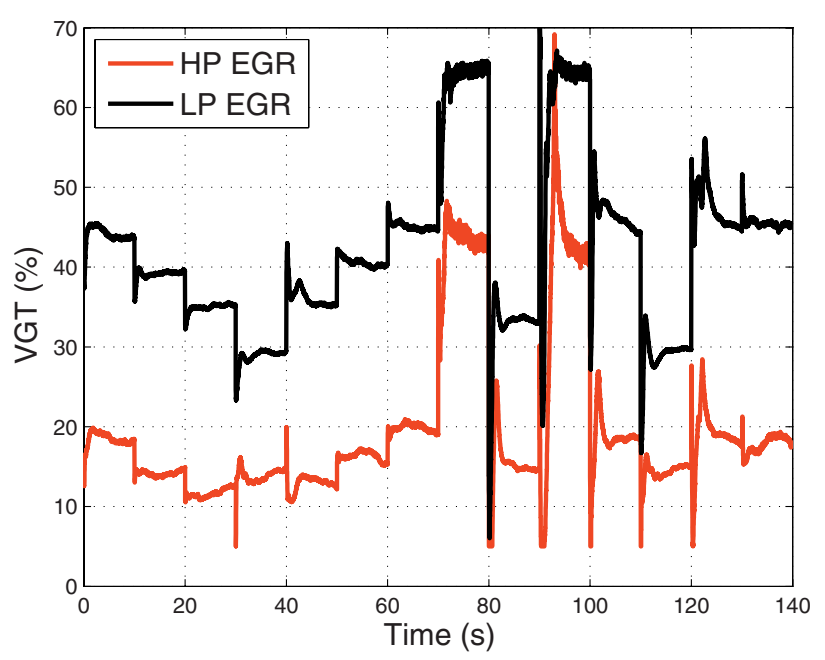

Figure 9

Turbocharger actuator with HP or LP EGR.

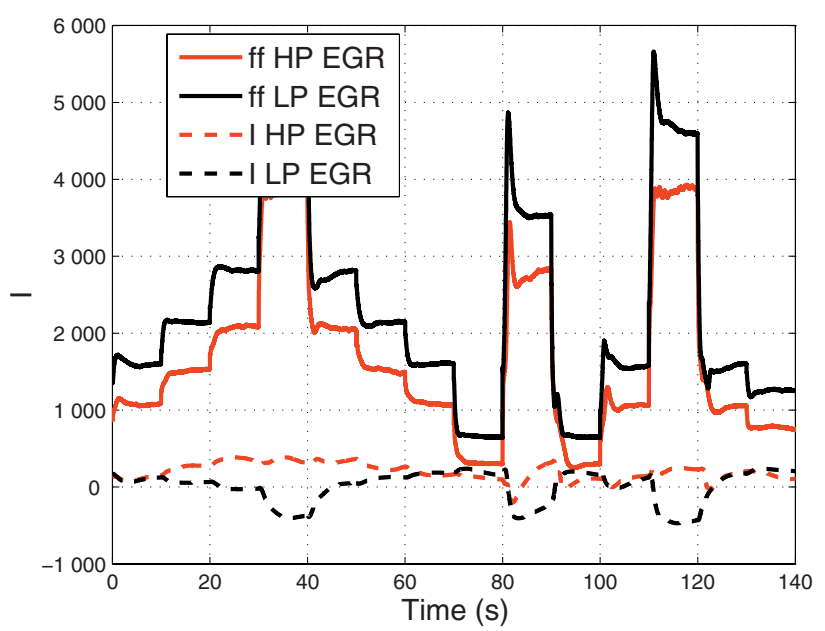

Figure 10

Controller terms with HP or LP EGR. I: integral term represented by $C$ in (15), ff: feedforward term equal to $\alpha_{2} \beta \psi_{c}\left(\Pi_{c, s p}\right)$ in (15). Note that the presented controller terms are in the unit of the power balance (in Watt).

\section{CONCLUSION}

different levels. However, the feedforward term takes well account of these effects. This validates the model and the assumptions made in its design.

The model provides a feedforward structure that takes into account the interaction of the turbocharger with other components, in particular the EGR circuit. The calibration of the turbocharger controller is independent of the choice of EGR loop, which reduces dramatically the calibration effort required.
This paper describes the development of a turbocharger model in a Diesel engine fitted with LP and HP EGR loops, and its reduction in order to provide a control oriented model. This work complements previous works already published or submitted ([3,4] and [1]). Experimental validation results are presented, justifying the assumptions made in the model reduction process.

The turbocharger control strategies designed from this model combined with an adequate EGR control and estimation provide a solid basis for the management of 
modern Diesel engines. In particular, the calibration of a complex air system could be a daunting task. In the proposed structure the effort required is greatly reduced thanks to an adequate physical representation of the system.

\section{REFERENCES}

1 Grondin O., Moulin P., Chauvin J. (2009) Control of a turbocharged engine fitted with high pressure and low pressure exhaust gas recirculation systems, in Proc. of the Control and Decision Conf., 2009.

2 Shutty J. (2009) Control strategy optimization for hybrid egr engines, in Proc. of the SAE conference, number 2009-011451.

3 Moulin P., Chauvin J., Youssef B. (2008) Modelling and control of the air system of a turbocharged gasoline engine, in Proc. of the IFAC World Conference, 2008.

4 Youssef B., Moulin P., Grondin O. (2007) Model based control of turbochargers: Application to a Diesel HCCI engine, in Proc. of the Conf. on Control Application, 2007.

5 Moraal P., Kolmanovsky I. (1999) Turbocharger modeling for automotive control applications, in Proc. of the SAE Conference, number 1999-01-0908.
6 Sorenson S., Hendricks E., Magnusson S., Bertelsen A. (2005) Compact and accurate turbocharger modelling for engine control. in Proc. of the SAE Conference, 2005.

7 Eriksson L. (2006) Modelling and control of turbocharger si and di engines, in Proceedings of ECOSM conference, 2006.

8 Jensen J., Kristensen A., Sorensen S., Houbak N., Hendricks E. (1991) Mean value modeling of a small turbocharged Diesel engine, in Proc. of the SAE Conference, number 910070.

9 Heywood J. (1988) Internal Combustion Engine Fundamentals, McGraw-Hill, Inc.

10 Khalil H. (1992) Nonlinear Systems, Prentice-Hall, Inc.

11 Kokotović P., O’Reilly O., Khalil H. (1999) Singular Perturbation Methods in Control: Analysis and Design, Soc. for Industrial \& Applied Math, 1999.

12 Moulin P., Grondin O., Chauvin J. (2010) Impact of egr on turbocharger control on a diesel engine with two egr loops, in Proc. of the IFAC Advance on Automotive Control, 2010.

Final manuscript received in February 2011 Published online in September 2011 